\title{
La filosofía como el imposible esfuerzo de nombrar el fundamento originario
}

Rebeca Maldonado

\author{
Crescenciano Grave, Naturaleza y existencia: Schelling \\ y el naufragio de la metafísica. México, UNAM, \\ Facultad de Filosofía y Letras, 2015. 280 pp.
}

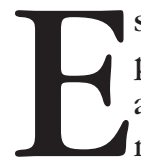

ste libro es una invitación a lo más inusual, un amor por las cosas perennemente más extrañas, un amor que no descansa de presentir aquello que no es inmediatamente dado pero de lo cual todo proviene, incluso en el pleno destierro del misterio que caracteriza a esta planicie de la modernidad sin fisuras, sin pasado ni futuro. El autor de Naturaleza y existencia: Schelling y el naufragio de la metafísica ha creado un libro filosóficamente perturbante, pues al "recibir los ecos distorsionados" del pensamiento de Schelling, intenta sin descanso a su vez la propia recreación y la rememoración del comienzo. Si no fuera el intento de Crescenciano Grave conducirnos a la experiencia trágica desde la increencia en el ente para devolvernos a cambio lo inhabitual de las cosas, su carácter renovadamente extraño; si no se dirigiera a esos buscadores hastiados ya del ente, este libro únicamente sería un libro de filosofía sobre un estante. Sería una mera exégesis de Schelling. Pero mi propuesta es que este libro no cae en esa categoría porque la materia gris, maleable, pastosa del caldero del ser burbujea en cada una de las páginas de este libro. Mi lectura no puede más que mantener y reavivar, junto con Crescenciano, el recuerdo del fondo originario burbujeante y vivo, y amartillar el cemento conceptual que impide ese recuerdo para recibir las señas que irradia Naturaleza y existencia. Schelling y el naufragio de la metafísica. Crescenciano Grave considera que los textos de Schelling -Investigaciones filosóficas sobre la esencia de la libertad humana y Las edades del mundo- constituyen la propuesta anti-idealista del filósofo y son una propuesta intempestiva de filosofía, de una filosofía contra su hoy porque piensa Crescenciano que el idealismo moderno no soporta la resistencia del fondo inescrutable, anulando más bien, "la resistencia activa a todo pensamiento" al disolver "lo incomprensible en el entendimiento alzando la filosofía como mera representación" (p. 116). 
Así, una pregunta que puede orientar la lectura de este libro es ¿por qué ante todo y ante nada emerge en el ser humano esa enorme insatisfacción a lo largo y a lo ancho de esta modernidad arrasadora, después de una onto-teología y un apego desmedido a lo ente y la pronta desaparición de todo lo sagrado? Reconocer ese descontento me parece que permite colocar la brújula hacia el comienzo, desde la enorme distancia que nos separa de él. Nostalgia irredenta que habita en el hombre ¿de qué? y ¿por qué? Naturaleza y existencia. El naufragio de la metafísica me parece que lo que hace es re-abrir un camino, una trayectoria, hacia el comienzo. Porque nuestra nostalgia es del comienzo en medio de la iterabilidad del ente. Crescenciano Grave Tirado: "escenifica el drama [del pensamiento de Schelling...] poniendo en los claroscuros de su lenguaje diferentes tentativas por acercarse [...] a esa verdad inaprehensible: el ser de los comienzos" (p. 11).

Dice Crescenciano Grave:

La ausencia de lo originario -su no aparecer como tal- en lo presente lleva al espíritu que lo busca a volcarse sobre sí mismo [...] Lo originario no se muestra como tal y esta ausencia lleva al espíritu a buscar lo insondable descubriendo con espanto que el presente formado y claro está sustentado en un pasado caótico que radicalmente lo precede (p. 109).

Una y otra vez, Crescenciano Grave otea en las profundidades schellingueanas, otea más allá, hacia el principio sustraído a representación y conceptos, porque Schelling señala la visión primera que reclama rememoración insistente, señalando así la única tarea pensante, ajena a las búsquedas de esto y lo otro, que emerge ahí donde el ente fracasa esencialmente: la tarea filosófica de reavivar el comienzo como búsqueda filosófica y del propio ser. Es urgente avistar el fondo originario. Es urgente atisbar lo que hay tras el principio de no contradicción y acceder a la contradicción misma.

De manera que la tarea del pensamiento originario schellinguiano es avistar tras el tiempo rectilíneo una temporalidad otra, "el tiempo del silencio y la quietud" a través de la evocación-rememoración, pues el ser humano mismo, a través de ella, es vínculo inmarcesible con el comienzo, sin embargo, pese a ello, "no puede expresar lo que encierra" (p. 105).

Lejos de la idea de logro y de éxito que acompaña a un pensar que impunemente ha establecido como criterio la evidencia, verdaderamente más allá, se alza un pensamiento para el cual uno sabe del carácter esencialmente fallido del pensar, porque el pensar es el intento, y digo intento, de expresar una y otra vez lo inexpresable, porque tal vez sea en contacto con lo IN- o con lo UN-, que aparece como en lo Unheimlich, entendido como un no estar 
esencialmente en casa, que el pensamiento nace. De este libro brotan otras tentativas, otros caminos, otras veredas dejando completamente caer toda idea de evidencia, claridad, distinción.

Para el pensar del comienzo schellinguiano, cálculo, deducción, claridad y distinción, son inútiles, este pensar lo inexpresable reclama antes bien rememoración y evocación. El ser humano es vínculo como señalaba con la naturaleza originaria y, por serlo, al remontarse hacia el origen, como Schelling lo hace, despierta o se alza, desde él mismo, la rememoración de lo que precede a lo acontecido.

Esta rememoración, que se alza desde el origen, sin embargo, "concentra el comienzo de los tiempos", y en ella lo que se muestra es lo "que no se puede distinguir". En dicha esencia indistinguible se cierra "el tesoro del pasado" y, sin embargo, la esencia no puede expresar nada. Si la rememoración es vínculo co-originario con el principio de todo, los principios contradictorios y en escisión de la oscuridad y de la luz, en su pugna alternativamente: uno intentará volver al saber originario y el otro pugnará por recibirlo y acogerlo en el saber. Así, el recuerdo de lo originario es lo que se aviva en el principio de la luz gracias al deseo que se despierta desde el principio inferior de volverse a la oscuridad, de cerrarse y replegarse en sí. De manera que el cerrarse, no inhibe el paso hacia la luz, lo reanima.

El pensar rememorante, señala Grave Tirado, requiere de la conversación interior, de la perseverancia en la búsqueda filosófica, es decir, de la dialéctica y de la historia, porque sabe narrar lo descubierto en el diálogo del alma que es "donde se avizoran las señales o las huellas del proceso que lleva desde el fondo más abismal, a la emergencia de la naturaleza organizada cuya clave [...] se encuentra en nosotros mismos" (p. 108).

Ir a lo insondable permite descubrir otros abismos como lo señala el autor y es que lo insondable no se muestra nunca como tal, lo cual lleva a su vez a su búsqueda y si es así es porque "el hombre comprende, no sin una especie de horror [...que el] ser primigenio hubo que poner algo como pasado antes de que fuera posible el tiempo presente, que esto pasado sigue estando oculto en el fondo y que el mismo principio que [dice Schelling] en su inoperatividad nos porta y sostiene, en su operatividad nos consumiría y aniquilaría" (pp. 109-110).

Así piensa Crescenciano Grave que el fondo originario no se anula sino que está presente sosteniendo al cosmos y que el organismo oculto sólo se revela como formación temporal, porque la forma se delinea desde el fondo. El principio de todo se expresa temporalmente. "La historia del ser no tiene un principio meramente ideal; [...] se expresa y presenta temporalmente" (p. 113).

Sin embargo, es necesario el arrebato contemplativo o la experiencia de la unidad indescriptible o la experiencia de lo indistinguible, aunque para 
expresarla sea indispensable separarse, porque el contenido de la experiencia inexpresable es expresable desde el entendimiento, al que le es propio "la separación y la distancia" y la rememoración.

En el pensar de la historia del ser de Schelling afirmar la desgarradura entre naturaleza y existencia, entre arrebato contemplativo y expresión, permite entender que el sistema "se sustenta en una resistencia cerrada al despliegue que, superada pero nunca suprimida o anulada, sostiene -funda- el desarrollo de toda existencia" (p. 114). Cierre y apertura, negación y afirmación, expresante y expresión se encuentran continua y circularmente en juego. El autor sostiene que "la continua rotación de todo lo existente se sostiene [...] en la contracción que se cierra a toda revelación" (p. 117).

El principio se describe como "unidad absoluta de sujeto y objeto", sin embargo, desde otra perspectiva, no debemos perder de vista la oposición eterna entre lo corporal y espiritual, luz y tinieblas, fuego y agua, masculino y femenino. El principio superior en Schelling descansa en el inferior, la conciencia en la inconciencia, lo alto en lo bajo, la luz en la oscuridad, el espíritu en la materia, que en su profundidad permanece incomprensible.

Lo que emerge desde la máxima tensión connotativa es el fondo infundado e incondicionado, sólo desde la confrontación con lo carente de límites, con ese enigma, el pensamiento se refiere a lo que precede a la razón y al concepto: a lo im-pensado. Él no está ni antes ni después del tiempo porque es lo que "en cada instante es por encima del tiempo" (p. 119). Es lo im-pensado mismo en su máxima radicalidad.

El tiempo está constituido contradictoriamente, por un principio que mueve al desarrollo y otro que se le opone. La oposición temporal es constitutiva de la realidad en devenir. Y esta dualidad que tiende hacia atrás y hacia delante, se manifiesta como voluntad, por un lado, de recogimiento y, por el otro, de exteriorización. Todo quiere permanecer en sí contraponiéndose, pero también todo quiere salir de sí manifestándose como lo que propiamente es. La tendencia de todo ser al reposo se ve conmovida por la atracción a la actividad. La contracción se opone a la expansión. Disputa interminable que según Crescenciano Grave es signo de la vida, porque sin contradicción, piensa Schelling, no habría vida.

Sin embargo, al ahondar en la paradoja de toda vida, en el sentido que por tender a la inmovilidad se ve conmovida por la movilidad, es que esa contradicción está presente a la vez que lo carente de contradicción. De este modo, detrás de la contradicción que es despliegue de tiempo está algo que no está en el tiempo y está por encima del tiempo. A lo que Schelling llama libertad. Tal es lo eterno, lo supremo e incondicionado. Éste no es ni mero ser ni mero ente, y no están uno fuera del otro, dado que son diferencia en unidad, son mismidad. 
Pensar la libertad carente de condicionamiento encuentra como señal el principio de contradicción. Lo incondicionado es la libertad, libertad de existir y no existir, de poder ser algo y no serlo, en tanto que es y no es ente y ser, y eso sólo puede ser voluntad. Esta voluntad es voluntad no decidida. Libertad incondicionada carente de contradicción es la voluntad que nada quiere. La primera idea es afirmación y negación; poder que no se ocupa de sí, poder que nada quiere. Tal libertad no quiere nada porque contiene todo (A y B). Coincidencia de sujeto y objeto, de esencia y ser, que "la razón filosófica, al confrontarse con lo que la excede, lleva su disposición metafísica hasta el límite porfiando por aludir [...o apuntar] al fondo inaccesible e insondable desde donde emerge toda revelación" (p. 129). Y el pensamiento hundiéndose en el mayor enigma de todos los tiempos "asume que sólo puede considerar cómo es que [lo infundado] alteró su sereno silencio interior" (p. 129). La interioridad del infundamento es Gelassenheit, absoluta dejadez, pero es ahí en lo absoluto de su serenidad que surge el deseo, el "ansia (Sehnsucht) de ir, encontrarse y tenerse" (p. 129). Y es que la voluntad que nada quiere "tampoco quiere desvanecerse en la nada y ese no querer ser nada abre en ella el resquicio donde se autogenera el deseo de buscarse a sí misma" (p. 129). Esa ansia es el comienzo de la existencia, es voluntad de existencia. Es el comienzo de lo operante. Es la voluntad eterna. Así: "La voluntad que nada quiere [...] no es el comienzo propiamente dicho" (p. 133). La voluntad de existencia es la que pone finalmente la posibilidad del tiempo, limitando a la libertad límpida de la eternidad. ¿De qué manera? A la manera del abandono de la indecisión, en la distinguibilidad entre necesidad y libertad en el acto. En cada acto, la voluntad de existir reviste de ser a la libertad y "este revestimiento es lo que necesariamente constituye el carácter de uno” (p. 257). El acto determinante del carácter "re-produce su existencia desde la forma singular del conflicto que lo constituye" (p. 257). El conflicto del ser humano es que "cada cual reconoce una libertad que es en sí necesidad", así "el carácter es nuestro ser más íntimo y, no obstante, las acciones que se siguen de él son libres" (p. 258). El carácter humano y el conflicto que lo constituye se expresa en los actos.

El mismo acto se re-produce en todos y, sin embargo, es distinto en cada caso: la esencia se reviste de ser caracterizándose de forma distinta y singular en la multiplicidad de los seres humanos. [...] Lo tremendo del origen repercute en la grandeza humana porque en ésta el delirio dionisiaco se ha transfigurado efectivamente en conciencia que, sin arredrarse ante lo ineluctable del carácter, lo inviste de sentido transfigurándolo en destino (p. 258). 
Las fuerzas contrapuestas primordiales se reproducen en cada individuo bajo una determinación individual. Pero, como dice Crescenciano Grave: "Lo que da el carácter a nuestra existencia es un fundamento exterior a nosotros mismos; lo que nos determina se nos escapa porque no disponemos de él" (p. 259), sino que más bien nos dispone anímicamente, encerrando en él el enigma de lo que somos.

Las edades del mundo a través de laberíntica coherencia confronta la modernidad y al pensar y cualquier idea de nosotros mismos sostenida en una claridad diáfana. Schelling nos confronta así a "un in-fundamento oscuro y caótico que ocultándose en tanto tal, sustenta eternamente el devenir de un cosmos y de una dispersión existencial" (p. 13). Este libro propone al principio originario como un conflicto entre fundamento y existencia, dando lugar, ya en el ámbito del pensamiento, a una metafísica trágica que reproduce una y otra vez el conflicto originario.

La tensionalidad entre la palabra portadora de la idea y la imposibiidad de nombrarla, hace a la metafísica un pensamiento aporético y paradójico, que deja tras de sí, vestigios y ruinas.

Crescenciano Grave coloca bajo sus propios términos el conflicto que en la actualidad nos atraviesa: decidirse a entregarse a la resolución transfiguradora o petrificarse en el mantenimiento del dominio contractivo. Y ¿qué es el dolor? El repercutir de la propia existencia conflictiva, el choque del ser consigo mismo que abre la posibilidad de la transfiguración.

Schelling, desde su tradición filosófica más olvidada, Boehme, Maestro Eckhart, Cusa, logra a su vez repercutir en los más grandes creadores filosóficos de nuestro tiempo, como Heidegger, Nishitani, Nishida, constituyéndose en un hito en el camino al pensar originario que Crescenciano Grave una y otra vez está determinado en señalar como lo hizo en Metafísica y tragedia $^{1}$ o en Schelling: el nacimiento de la filosofía trágica moderna ${ }^{2}$ desde un pensamiento lúcido, el cual, aspira al concepto, pero sin renunciar nunca a la oscuridad que nos constituye. El pensar que Martin Heidegger presenta en Das Ereignis o Sobre el comienzo, La historia del ser no es más que un seguir las sendas del autor de Las edades del mundo y de Las investigaciones filosóficas sobre la esencia de la libertad humana y que se expresa en sus conceptos de comienzo, historia del ser, fundamento, in-fundamento, decisión/indecisión. La escuela de Kioto pasó por los abismos schellinguianos como un auténtico interlocutor que permitiría a su vez dilucidar la propia vacuidad budista en esa anterioridad que no es ni sujeto ni objeto. Gracias al libro de Crescenciano

${ }^{1}$ Vid. Crescenciano Grave, Metafísica y tragedia. Un ensayo sobre Schelling. México, Ediciones sin Nombre/UnAm, Facultad de Filosofía y Letras, 2008.

${ }^{2}$ Vid. C. Grave, Schelling: el nacimiento de la filosofía trágica moderna. México, UNAM, 2011. 
Grave comprendemos que es Schelling el pensador que ha contribuido en gran medida a desfondar la modernidad y su instancia subjetiva refiriéndola a algo mucho más amplio e inaprensible. La contribución que Crescenciano Grave ha hecho a la filosofía en español abona a la gran tarea de la filosofía de hacer oscilar nuestros sí mismos y nuestro tiempo, des-endurecer los marcos vigentes de pensar, des-entumecernos, permaneciendo en el insoportable entre de lo expresante y expresable lugar de la esencia del dolor. Éste no es un dolor casual, soportar la escisión del ser, es el pathos del filósofo.

Lo aquí dicho sobre Naturaleza y existencia: Schelling y el naufragio de la metafísica ha sido si acaso una señal, una invitación, de lo que en él es inagotable e inexpresable. Quiero terminar brevemente con unas palabras de Meister Eckhart: "Para quien haya echado una mirada, aunque sólo sea un instante, sobre ese fondo, cien marcos acuñados en oro es moneda falsa". ${ }^{3}$

${ }^{3}$ Maestro Eckhart, "Vivir sin porqué", en El fruto de la nada. Madrid, Siruela, 2008, p. 49. 